\title{
An underestimated blood parameter before myeloproliferative neoplasm diagnosis: the case of thrombocytosis and the delayed essential thrombocytemia diagnosis
}

Background:Thrombocytosis, i.e. platelet count $>400.000 / \mu \mathrm{L}$ in peripheral blood, is also due to Essential Thrombocythemia $(\mathrm{ET})$, and delaying the diagnosis of thrombocytosis might coincide with a delayed ET diagnosis.

The purpose of our study was to investigate the factors virtually leading to a delay in ET diagnosis.

Methods: We analyzed the interval between the first evidence of thrombocytosis and ET diagnosis, and defined it as ETunderestimation-period (ET-uP). We analyzed 280 ET patients followed at our Institution. To verify possible correlations with ET-uP, we investigated patients' ages, gender, history of vascular complications, thrombocytosis, splenomegaly, and marrow fibrosis degree. We also considered their General Practitioners (GP) characteristics: age, personal computer use, number of patient visits in the two years before diagnosis.

Univariate logistic analysis for each parameter was performed using the Spearman's rank correlation coefficient to assess correlation with ET-uP. Multivariate logistic regression analysis was performed on the parameters that resulted significant at the previous analyses. The logistic regression analysis was performed dichotomizing the ET-uP variable using its median value.

Results: Median ET-uP was 16 months (range 1-240). The analysis showed that a shorter ET-uP correlated with thrombocytosis $(p<0.001)$ and previous cardiovascular events $(p=0.04)$. At multivariate analysis, the Area. Under the Curve (AUC) of the (Receiver Operating Characteristic) ROC curve was 0.72 . No correlation was found analyzing GP data.

Conclusion: Our results underline a deficient medical practice, and prompt for corrective actions (use of more restrictive normal range for platelet count-with lower upper limit and warning flags for pathological findings) to timely commence the diagnostic workup of this condition.

\section{KEYWORDS: thrombocytosis, platelet count, essential thrombocythemia, general practitioner}

\section{Introduction}

In clinical practice, the normal range of platelet count is considered to be between 150.000 and 450.000 thrombocytes per $\mu \mathrm{L}[1]$. However, this upper limit is currently being reconsidered following the development of myeloproliferative molecular markers able to refer even mild thrombocytosis (i.e. 400.000/L) to a bone marrow disease [2-8]. Indeed, a notable study carried out on a healthy Italian population reported as upper limit 400.000 and 360.000 thrombocytes per $\mu \mathrm{L}$ for women and men, respectively [9].

Essential thrombocythemia (ET) is a chronic myeloproliferative disorder [10-13]. It is a clonal pathology of unknown etiology deriving from the transformation of a pluripotent progenitor cell. ET is characterized by persistent overproduction of platelets $(>450.000 / \mu \mathrm{L})$ without marrow fibrosis or equal amounts of other hematopoietic lines [14,15]. As many occasional findings in patients undergoing blood tests for other conditions or routine checkups. Furthermore, in many cases the diagnosis is made during medical tests following a vascular accident $[16,17]$ and, in our experience, thrombocytosis is already present in the patient's past history even before the event has occurred. Only then is thrombocytosis eventually taken into account.

Due to the wealth of data on the evidence of as 50 to $70 \%$ of thrombocytosis diagnoses are
Vincenzo Martinelli ${ }^{1}$, Laura Cella², Novella Pugliese ${ }^{* 1}$, Ilaria Cappuccio ${ }^{1}$, Ida Rosa Scognamiglio ${ }^{1}$, Luana Marano ${ }^{1}$, Luigia Simeone ${ }^{1}$, Giulia Campagna ${ }^{1}$, Marco Picardi ${ }^{1}$ \& Fabrizio Pane ${ }^{1}$

${ }^{1}$ Hematology Unit, Department of Clinical Medicine and Surgery, Federico II Medical School, Naples, Italy

${ }^{2}$ Institute of Biostructure and Bioimaging, National Research Council (CNR) Naples, Italy

*Author for correspondence: novypugliese@yahoo.it 
pathological platelet count left uninvestigated in a patient's past history, we analyzed the factors virtually leading to a delay in the diagnosis of ET.

\section{Materials and methods}

The study population comprised 280 consecutive patients diagnosed with ET from January 2000 to June 2015, and referred to the Hematology Unit of the Department of Clinical Medicine and Surgery of the Federico II Medical School in Naples. All patients gave their written informed consent to participate in the study.

ET was diagnosed according to the 2008 WHO criteria [18]. For patients diagnosed before this date, we ascertained that the investigations were nevertheless in line with those standards. The presence of familial thrombocytosis was ruled out. Spleen volume was evaluated by ultrasonography scans [19] at diagnosis in $274 / 280$ patients. Inclusion criteria were normal red cell morphology, absence of blood cell precursors, and CD34 positive cells in peripheral blood within normal ranges. Bone marrow biopsy specimens were available for 229/280 patients. Marrow fibrosis (MF) [20] was absent in 136 and described as grade $0 \mathrm{MF}$ [20] in 93 of them. We did not consider these data as a limit because our main aim was to understand the reason for the underestimation of thrombocytosis, which can be found in both cases. Patient characteristics were age, gender, history of vascular events, thrombocytosis grade, splenomegaly and bone marrow fibrosis [TABLE 1]. We also collected data regarding the patients' General Practitioners (GP), namely age, checkups (number/year) and Personal Computer (PC) use, by interviewing 249/280 patients. The rationale for the choice of each variable is reported in TABLE 1.

For each patient we identified the time interval between the first finding of high platelet count and ET diagnosis, defining this interval as underestimation period, and this condition as Essential Thrombocythemia underestimation period (ET-uP).

The first finding of high platelet count was obtained through blood count data recorded in the patient's past history, in the absence of any active and concomitant co-morbidity. Furthermore, data on past history were also used to exclude intercurrent pathological events that may have caused thrombocytosis. Furthermore we looked for correlations between patients and GP characteristics, and ET-uP.

\begin{tabular}{|c|c|}
\hline Table 1. Baseline patient characteristics at the time of Essential Thrombocythemia diagnosis. \\
\hline Characteristics & No. \\
\hline Number of patients & 280 \\
\hline Male/female & $125 / 155$ \\
\hline Age year median (range) & $53(16-95)$ \\
\hline Platelets count $(\times 109 / \mathrm{L})$ median (range) & $543(400-2065)$ \\
\hline Splenomegaly & $162 / 274(59 \%)$ \\
\hline Patients with CV event(s) & $52(18.6 \%)$ \\
\hline Reticulin fibre score (20) analysis & 229 \\
\hline Absence of fibrosis & $136(59.3 \%)$ \\
\hline MF(20)=0 & $93(40.6 \%)$ \\
\hline JAK2v617f mutated/wild type & $174 / 280(62 \%)$ \\
\hline Presence of CV risk factors & $207(74 \%)$ \\
\hline Overall no. of previous CV events & $58(20.7 \%)$ \\
\hline Ongoing antiaggregant therapy & $58(20.7 \%)$ \\
\hline
\end{tabular}

Patient and General Practitioner (GP) variables.

\begin{tabular}{|c|c|c|}
\hline & & Rationale for the choice of the variable \\
\hline \multirow{7}{*}{ Patient } & Age & Number of visits in relation to age and comorbidity \\
\hline & Gender & $\begin{array}{l}\text { Trend to more frequent visits during pregnancies, or for iron } \\
\text { deficiency related to menses }\end{array}$ \\
\hline & Previous vascular event & Greater attention to health care, with more frequent blood testing \\
\hline & Thrombocytosis grade & Greater doctor alert to health condition \\
\hline & Splenomegaly & Greater attention to health care, with more frequent blood testing \\
\hline & Bone marrow fibrosis & $\begin{array}{l}\text { First diagnosis of thrombocytosis and possible ET reticulum fiber } \\
\text { score progression }\end{array}$ \\
\hline & Age & Different self-updating modality \\
\hline \multirow{2}{*}{ GP } & PC use & Possible automated warning flags \\
\hline & Number of visit per year & Greater likelihood of detecting thrombocytosis \\
\hline
\end{tabular}


Data on the JAK2 mutant allele burden, presence of CAL-R mutation and MPL are not available for this cohort of patients. In any case, thrombocytosis is the common denominator in all these molecular alterations.

\section{- Statistical analysis}

Categorical variables were expressed as percentages; median and range were used to describe all continuous variables. Patient- and GP-related variables were examined according to ET-uP by univariate statistical methods. Univariate logistic analysis for each parameter was performed using the Spearman's rank correlation (Rs) coefficient to assess correlation with ET-uP.

Multivariate logistic regression analysis was performed on the parameters that resulted significant at the previous analyses. In order to perform logistic regression, the ET-uP variable was dichotomized using its median value.

The logistic regression model is:

$$
P\left(x_{i}\right)=\frac{e^{g\left(x_{i}\right)}}{1+e^{g\left(x_{i}\right)}}, i=1, \ldots, m
$$

With,

$$
g_{i}(x)=\beta_{0}+\beta_{1} x_{i 1}+\beta_{2} x_{i 2}+\ldots \beta_{n} x_{i n}
$$

Where $m$ is the number of patients, $x_{1}, x_{2} \ldots$ $\mathrm{x}_{\mathrm{n}}$ represent different input variables and $\beta_{0}$, $\beta \quad \beta$ the corresponding regression coefficients. For the selection of variables, a stepwise method (Wald-Enter method, $\mathrm{p}=0.05$ for entry into the model and $p=0.10$ for removal from the model) was performed. Model performance was evaluated by the area under the receiver operating characteristic (ROC) curve (AUC). Statistical analysis was performed with SPSS 18.0.

\section{Results}

Median ET-uP was 16 months (range: 1-240). Results of univariate analysis for the patient variables analyzed are reported in TABLE 2. The only variables that resulted significantly correlated with ET-uP were degree of thrombocytosis and a history of cardiovascular (CV) complications. Both variables were inversely correlated with ET-uP [TABLE 2, FIGURE 1 and 2], with an increase in the former being associated to a reduced underestimation time of thrombocytosis. None of the GPs' variables was correlated with ET-uP. Applying multivariate logistic regression with a dichotomized ET-uP to a 16-month median value ( 0 if $\mathrm{ET}-\mathrm{uP}<16,1$ otherwise), both thrombocythemia and history of cardiovascular complications resulted to be independent predictors of the underestimation period (estimated coefficient for CV events: -0.682, Odds Ratio (OR) 0.506 p=0.042; estimated

\begin{tabular}{|c|c|c|c|}
\hline \multirow[b]{2}{*}{ Characteristics } & \multirow[b]{3}{*}{ Median (range) } & \multicolumn{2}{|c|}{ Univariate analysis } \\
\hline & & \multirow[t]{2}{*}{ Rs } & \multirow[t]{2}{*}{$\mathrm{p}$-value } \\
\hline Continuous variables & & & \\
\hline $\begin{array}{l}\text { Age (years) } \\
\text { Platelets }\left(10^{\wedge} 5\right)\end{array}$ & $\begin{array}{c}53(16-95) \\
5.43(4.00-20.65)\end{array}$ & $\begin{array}{c}0.94 \\
-0.432\end{array}$ & $\begin{array}{c}0.12 \\
<0.001\end{array}$ \\
\hline Categorical variables & $\mathrm{N}(\%)$ & & \\
\hline \multicolumn{4}{|l|}{ Gender } \\
\hline $\begin{array}{l}\text { Female } \\
\text { Male }\end{array}$ & $\begin{array}{l}155(55.4) \\
125(44.6)\end{array}$ & 0.054 & 0.376 \\
\hline \multicolumn{4}{|l|}{ Splenomegaly $(\mathrm{n}=274)$} \\
\hline $\begin{array}{l}\text { Yes } \\
\text { No }\end{array}$ & $\begin{array}{l}162(59.1) \\
112(40.9)\end{array}$ & -0.17 & 0.779 \\
\hline \multicolumn{4}{|l|}{ Bone marrow fibrosis ${ }^{(18)}(\mathrm{n}=229)$} \\
\hline $\begin{array}{l}\text { Absent } \\
\text { Early MF }\end{array}$ & $\begin{array}{l}136(59.4) \\
92(40.6)\end{array}$ & -0.69 & 0.308 \\
\hline \multicolumn{4}{|l|}{ Cardiovascular risk factor } \\
\hline $\begin{array}{l}\text { Yes } \\
\text { No }\end{array}$ & $\begin{array}{l}207(73.9) \\
73(26.1)\end{array}$ & -0.38 & 5.30 \\
\hline History of cardiovascular events & 273 & & \\
\hline $\begin{array}{l}\text { Yes } \\
\text { No }\end{array}$ & $\begin{array}{c}52(19.0) \\
221(81.0)\end{array}$ & -0.122 & 0.044 \\
\hline \multicolumn{4}{|l|}{ Ongoing antiaggregating therapy } \\
\hline $\begin{array}{l}\text { Yes } \\
\text { No }\end{array}$ & $\begin{array}{l}125(44.6) \\
155(55.3)\end{array}$ & -0.150 & 0.410 \\
\hline
\end{tabular}
coefficient for degree of thrombocytosis: -0.418 , 
OR $0.659, \mathrm{p}<0.001)$. The resulting model exhibited a good predictive performance, being characterized by an AUC $=0.72$ (95\% Confidence Interval (CI) 0.66-0.78) [FIGURE 3]. In FIGURE 4, the probability of having an ET-uP greater than 16 months as a function of platelet count for patients with or without a history of cardiovascular events is plotted.

We failed to find any correlation between ET-uP and GP characteristics, (age: $\mathrm{p}=0.3, \mathrm{PC}$ use: $\mathrm{p}=0.7$, number of checkups in the two years prior to diagnosis: $p=0.7$ ). Nevertheless, it is reasonable to underline the finding of an inadequate number of checkups, including physical examinations per year, and the surprising amount of data on the number of examinations per year in non splenomegalic patients compared to splenomegalic ones: 4 (range, $0-20$ ) vs. 2 (range, $0-14$ ).

\section{Discussion}

The parameters employed in our study show

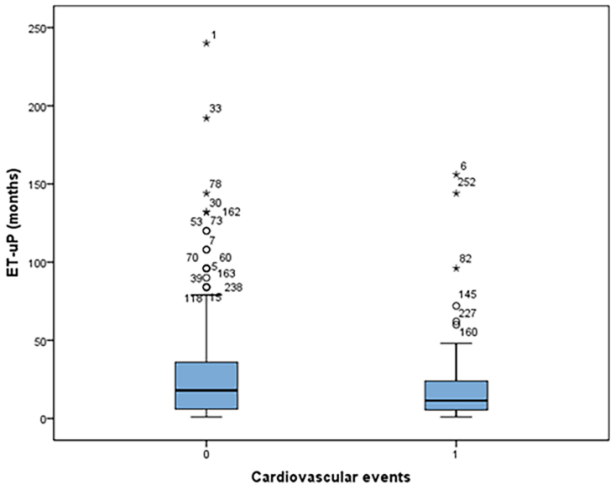

FIGURE 1. Essential Thrombocythemia underestimation period (ET-up) and history of cardiovascular (CV) events. Comparison of ET-up in patients with a history of cardiovascular events (1) and patients without (0).

Patients with CV events: 52. Median ET-uP: 11.5 months (range: 1-156)

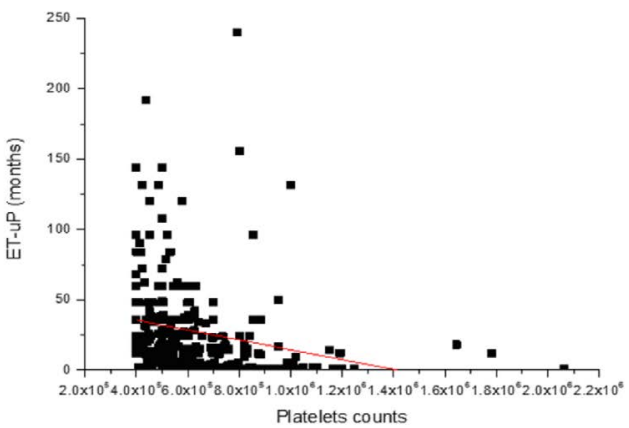

FIGURE 2. Essential Thrombocythemia underestimation period and thrombocytosis. In red, fitted linear regression model.

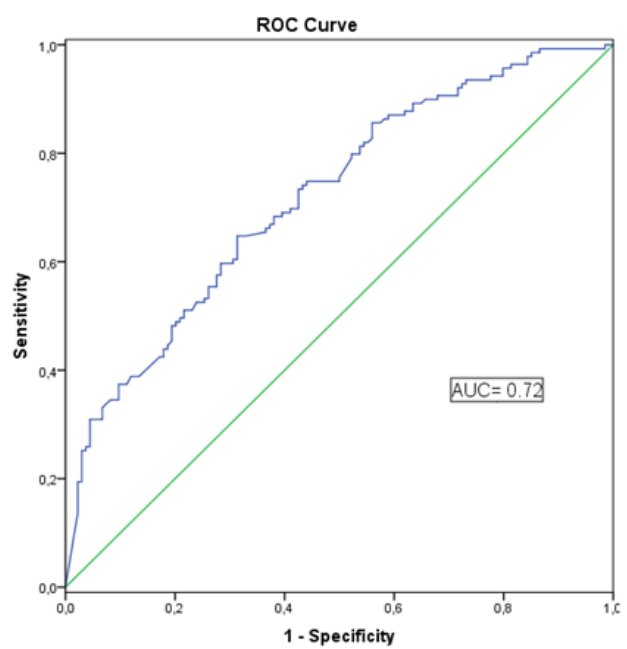

FIGURE 3. ROC curve of the logistic regression model including as predictive variables thrombocythemia (platelet counts) and history of cardiovascular complications. The AUC $=0.72$ indicates a good predictive performance for ET-uP model prediction.

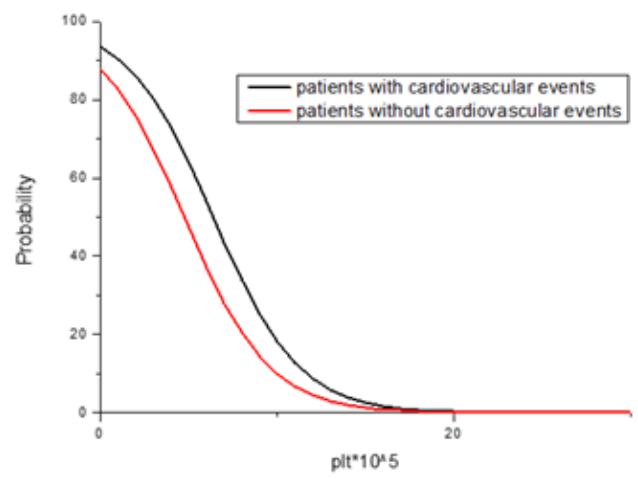

FIGURE 4. Probability of ET-uP > 16 months as a function of platelets counts for patients with a history of cardiovascular events and patients without.

a statistically significant correlation between ET$\mathrm{uP}$ and thrombocytosis level, and a history of cardiovascular complications.

In our population sample, fifty-two of the 280 patients $(18.6 \%)$ had experienced mild to severe thrombo-hemorrhagic episode(s) before the diagnosis. In this sub-group, the median ETuP was 11.5 months (range 1-156). These events cannot be exclusively ascribed to thrombocytosis, as $74 \%$ of patients had other cardiovascular risk factors (hypertension, diabetes, smoking status, overweight/obesity) - although thrombocytosis may have played a synergistic role.

To the best of our knowledge, this is the first study analyzing the underestimation period for ET diagnosis in such a large cohort of patients and in a multivariate fashion.

There are two main limitations of our study. 

diagnosis

First, it is impossible to discover the real time of the first increase in platelet count, since in common clinical practice not all people perform blood counts every six months or annually and, furthermore, not all people, conventionally, retain old laboratory exams. The first evidence of thrombocytosis could represent a good surrogate of ET insurgence. Secondly, this is a retrospective study, with all the related limitations.

Similar parameters, analyzed in our study, and in particular the presence of cardiovascular risk factors, have been recently employed to study the underestimation of myeloproliferative neoplasms (MPNs) [21]. The multicenter study by Enblom et al. focused on the long underdiagnosis period of MPNs, the possible factors influencing this condition, as well as the possible consequences - such as any cardiovascular episodes. In this study, as many as 272 of the 612 MPNs patients were ET. The authors stressed the concept that an MPNs should always be suspected in patients with unexplained elevated hematocrit, leukocyte and/or platelets counts. At variance, our study analyzed the timing of diagnosis for 280 ET patients. The multivariate analysis was performed using as ideal predictive model either one or two variables, including thrombocytosis and a history of cardiovascular complications. A shorter ET-uP was determined by the degree of thrombocytosis and a past history of cardiovascular complications. The AUC of the ROC curve representing the logistic regression model was 0.72 , tending to a statistically significant value.

There is still insufficient knowledge of the factors influencing ET-uP. It seems nevertheless clear how a delay in identifying the altered platelet count could influence the possible development of thrombotic and hemorrhagic episodes during the misdiagnosis period, increasing the patient's risk and thus representing the main cause of morbidity in ET patients [21,22].

Detecting and assessing thrombocytosis is undoubtedly clinically relevant. Consistently with ET Guidelines [22], patients without specific risk factors need only to be kept under observation; they nevertheless undergo additional follow-up visits, paying careful attention to possible ensuing comorbidities.

As additional aim, we analyzed the "General Practioner's side" to identify possible factors influencing ET-uP; for this purpose, we considered GP's age, computer use and number of visits the participants to our study had undergone.

Although no relationship was found with the parameters considered, the data collected indicate a relationship between a small number of examinations and a frequent underestimation of splenomegaly and platelet count. Conversely, GP's age and PC usage were found to be irrelevant.

We can only speculate that the underestimation may be related to: (i) little attention to the normal value ranges for platelet count; (ii) frequent asymptomatic thrombocythemia, at variance with thrombocytopenia, (iii) use of anti-aggregant therapy, possibly leading to an improper attention to platelet count.

It is worth underlining that the delayed diagnosis is not due to long waiting lists. In fact, in compliance with the regulations of the Health System of the Campania Region, when a GP or any other accredited physician comes across altered hematological values, referral to a specialist occurs within 2-3 weeks [23]. Nonetheless, as the interval in our case series was even shorter, the delay was irrelevant in relation to ET-uP.

The frequent evidence of long ET-uP deserves attention, as it suggests the need for a timely diagnosis and a more thorough diagnostic workup of this condition. Hematologist should prompt for the use of a more restrictive range for platelets count - especially for the upper limit and/or a more evident warning flag, especially in relation to age and gender, as a tool of alert.

\section{Partnership}

VM designed the research study; VM, NP, IC, IS, LM, LS, GC collected clinical data; MP contributed to a diagnostic tool to determine spleen volume; LC analyzed the data; FP supervised the paper; VM and LC wrote the paper.

\section{Acknowledgments}

The authors are grateful to Rosanna Scala for the language editing.

\section{Conflict of Interest}

The authors have no conflict of interest to declare. 


\section{REFERENCES}

Ross DW, Ayscue LH, Watson J, Bentley SA. Stability of hematologic parameters in healthy subjects. Intraindividual versus interindividual variation. $A m$. $J$. Clin. Pathol. 90, 262-267 (1988).

Sacchi S, Vinci G, Gugliotta L, et. al. Diagnosis of essential thrombocythemia at platelet counts between 400 and 600x10(9)/L. Gruppo Italiano Malattie Mieloproliferative Croniche (GIMMC). Haematologica 85, 492-495 (2000).

Baxter EJ, Scott LM, Campbell PJ, et al. Cancer Genome Project. Acquired mutation of the tyrosine kinase JAK2 in human myeloproliferative disorders. Lancet 365, 1054-1061 (2005).

Levine RL, Pardanani A, Tefferi A, Gilliland DG. Role of JAK2 in the pathogenesis and therapy Of Myeloproliferative disorders. Nat. Rev. Cancer 7, 623-683 (2007).

Campregher PV, Santos FP, Perini GF, Hamerschlak N. Molecular biology of Philadelphia-negative myeloproliferative neoplasms. Rev. Bras. Hematol. Hemoter. 34, 150-155 (2012).

Klampfl T, Gisslinger H, Harutyunyan AS, et al. Somatic mutations of calreticulin in myeloproliferative neoplasms. $N$. Engl. J. Med. 369, 2379-2390 (2013).

Nangalia J, Massie CE, Baxter EJ, et al. Somatic CARL mutations in myeloproliferative neoplasms with nonmutated JAK2. N. Engl. J. Med. 369, 2391-2405 (2013).

Rumi E, Pietra D, Ferretti V, et al. Associazione Italiana per la Ricerca sul Cancro Gruppo Italiano Malattie Mieloproliferative Investigators. JAK2 or CARL mutation status defines subtypes of essential thrombocythemia with substantially different clinical course and outcomes. Blood 123, 1544-1551 (2014).

Biino G, Santimone I, Minelli C, et al. Age- and sex-related variations in platelet count in Italy: a proposal of reference ranges based on 40987 subjects' data. PLoS One 8, e54289 (2013).

Epstein E, Goedel A. Hämorrhagische Thrombozythämie bei vascularer Schrumpfmilz. Virchows Archiv. A. Pathol. Anat. Histopathol. 293, 233 (1934).

Dameshek W. Some speculations on the Myeloproliferative Syndromes. Blood 6, 372-375 (1951).

Mesa RA, Silverstein MN, Jacobsen SJ, Wollen PC, Tefferi A. Populationbased incidence and survival figures in essential thrombocythemia and agnogenic myeloid metaplasia: an Olmsted County Study, 1976-1995. Am. J. Hematolo. 61, 10-15 (1999).

Beatrice JM, Garanito MP. Essential thrombocythemia: a rare disease in childhood. Rev. Bras. Hematol. Hemoter. 35, 287-289 (2013).

Turhan AG, Cashman JD, Eaves CJ, Humphries RK, Eaves AC. Variable expression of features of normal and neoplastic stem cells in patients with thrombocytosis. Br. J. Haematol. 82, 50-57 (1992).

El Kassar N, Hetet G, Briere J,Grandchamp B. Clonality analysis of hematopoiesis in essential thrombocythaemia: Advantages of studying $T$ lymphocytes and platelets. Blood 89, 128-134 (1997).

Colombi M, Radaelli F, Zocchi L. Maiolo AT. Thrombotic and hemorrhagic complications in essential thrombocythemia. A retrospective study of 103 patients. Cancer 67, 2926-2930 (1991).

Jensen MK, de Nully Brown P, Nielsen OJ, Hasselbalch HC. Incidence, clinical features and outcome of essential thrombocythaemia in a well-defined geographical area. Eur. J. Haematol. 65, 132-139 (2000).

Vardiman JW, Thiele J, Arber DA, et al. The 2008 revision of the World Health Organization (WHO) classification of myeloid neoplasms and acute leukemia: rationale and important changes. Blood 114, 937-951 (2009).

Picardi M, Martinelli V, Ciancia R, et al. Measurement of spleen volume by ultrasound scanning in patients with thrombocytosis: a prospective study. Blood 99, 4228-4230 (2002).

Thiele J, Kvasnicka HM: Grade of bone marrow fibrosis is associated with relevant hematological findings-a clinicopathological study on 865 patients with chronic idiopathic myelofibrosis. Ann. Hematol. 85, 22632 (2006).

Enblom A, Lindskog E, Hasselbalch H, et al. High rate of abnormal blood values and vascular complications before diagnosis of myeloproliferative neoplasms. Eur. J. Med. 26, 344-347 (2015).

Tefferi A, Barbui T. Polycythemia vera and essential thrombocythemia: 2015 update on diagnosis, risk-stratification and management. Am. J. Hematol. 90,162-173 (2015).

http://www.agenas.it/aree-tematiche/ qualita/tempi-e-liste-diattesa?jjj $=1498481105551$ 